\title{
A Dynamic Theory of Cooperatives: The Link Between Efficiency and Valuation
}

\author{
Lewis Evans and Graeme Guthrie
}

New Zealand Institute for the Study of Competition and Regulation

13 July, 2002

\begin{abstract}
Cooperative and mutual organisational forms arise for reasons that include contracting problems between parties. Economic literature suggests a variety of allocative inefficiencies implied by these forms that largely have their origins in poor investment decisions. We demonstrate that a multi-period model and the supplier and cooperative valuations it implies are essential for understanding the sources of inefficiency and solutions to them. Using the case of a supplier cooperative we show that economic inefficiency arises because of the common over-supply of input induced by suppliers responding to average, rather than marginal, revenue, and that investment is actually efficient given the supply of input. The presence of unowned capital is an important source of over-supply. We show that if the cooperative's shares are priced at the present value of expected dividends and supplier entry and exit decisions are taken solely on the basis of profitability of membership then there is no inefficiency and we describe a functioning example. Finally, our valuations show that that there is no "time horizon" investment problem, at least from an industry perspective.
\end{abstract}

The authors gratefully acknowledge the Ministry of Agriculture and Forestry for financial support, Neil Quigley and Institute seminar participants at Victoria University of Wellington for helpful comments, and Steen Videbeck for research assistance. The views expressed in this paper are those of the authors alone. 


\section{A Dynamic Theory of Cooperatives: The Link Between Efficiency and Valuation}

\section{Introduction}

Cooperative or mutual entities come in a wide variety of industries, organisational forms, and points in supply and demand chains. ${ }^{1}$ They each have the characteristic that the owners supply inputs or obtain outputs from the entity and receive a return from ownership which is somehow tied to patronage. We consider the particular, but typical, input-supplier cooperative in which suppliers have to be members, hold shares in the enterprise, and participate in governance by means of the choice of directors. Suppliers produce an input for downstream processing and, perhaps, distribution and marketing by means of the cooperative. This example fits closely the case of dairy cooperatives, where farmers provide milk to a cooperative processor, but it is not limited to them. ${ }^{2}$ We assume the traditional cooperative arrangement tying shares and payout to the amount of input supplied, where the shares are priced at some value that may be nominal, even zero.

Our contribution is threefold. Firstly, we show that an intertemporal model is essential in understanding the economic efficiency of the tying practice. Secondly, we clarify the source of inefficiency, and show that it arises from the over-supply of input, and not necessarily from investment. Given the raw material supplied, the cooperative employs the same capital stock as would an investor-owned firm, but the way in which the capital stock is financed distorts input supply. Thirdly, we utilise implied valuations of the cooperative to demonstrate that economic efficiency obtains under cooperative ownership providing the shares are priced in a way that values the enterprise as the present value of its prospective earnings. When there are minimal impediments to supplier entry or exit the cooperative has an incentive to value shares in this manner, and in a competitive industry cooperatives will, we argue, be forced to do so whether or not they have restricted entry and exit. ${ }^{3}$ We provide an example of a dairy cooperative that has implemented such "fair value" share pricing. This new cooperative set-up implies efficient levels of production (and, in this case, that industry profitability is maximized). In our dairy cooperative example, farmers are paid the wholesale price of milk; all profits are distributed to farmers in their role as shareholders; and shares are nontransferable and tied to milk supplied. This seemingly cosmetic

\footnotetext{
${ }^{1}$ For a review of the range of cooperative structures see Hansmann (1996).

${ }^{2}$ Hansmann (1996) provides a discussion of contracting issues and product characteristics that tend to predicate cooperative organisational forms.

${ }^{3}$ This statement presumes that the contracting and local bilateral monopoly problems that cooperatives have been used to address do not outweigh the inefficiencies that relate to share pricing and ownership. Cooperatives may restrict input by not admitting new entrants and limiting the supplies of existing suppliers. They may limit supply reductions by imposing long and costly exit conditions.
} 
unbundling affects farmers' production decisions because the share price is set by a third party at the present value of the future dividend stream.

Bonin, Jones and Putterman (1993) review the empirical and theoretical literature on producer cooperatives, or labour-managed firms. They do not consider consumer and marketing cooperatives directly and they emphasise investment inefficiency. The theory they survey focusses on the consequences of replacing profit maximization with some other objective function (Bonin et al. 1993, p. 1316) and not intertemporal choice. Our result explains the over-investment that they report in a range of studies. Studies that consider departures from profit maximisation include Ward (1958) who uses "per capita valued added in production net of capital (financing) costs" as the objective function and allows the cooperative to choose the level of labour input. Clark (1952) proposes purchasing cooperatives minimize per-unit costs and that marketing cooperatives maximize per-unit returns. Anderson, Porter and Maurice (1979) assume a representative member maximizes its own utility function. Helmberger and Hoos (1962) assume that the cooperative has decentralized decision-making and profit-motivated members. We follow this approach, extending their model to multiple time periods, which allows us to analyze investment decision-making.

Jensen and Meckling (1979) list problems associated with the cooperative structure. The horizon problem, as it is termed, arises when suppliers have claims on cashflows which are contingent on supplying raw materials. When they leave the cooperative, the assets they financed (through retained earnings) remain. Returns must be high to compensate the supplier for both the interest forgone and the principal. Bonin et al. (1993, p. 1309) list two solutions: departing members can sell their shares to new members, or each departing member can be reimbursed for past contributions to the cooperative's capital "equivalent to his share of the discounted value of future returns to these investments." The basic result from the property rights approach is that the cooperatives will have restricted access to debt, and will under-invest relative to investor-owned firms if they only use internal funds to finance capital (Bonin et al. 1993, p. 1311). The horizon problem is also discussed by Porter and Scully (1987, pp. 495-496), who suggest a partial solution involving revolving finance. We show by our consideration of cooperative and supplier-business valuations implied by our intertemporal model that the horizon problem does not exist, at least for the cooperative as distinct from its individual suppliers.

The horizon problem is closely related to the common property problem - if membership is open to anyone at a nominal, say zero, price new members acquire the same claims on existing assets as old members. This problem will arise when investment decisions are made, again leading to under-investment. The common property problem arises in the context of a lack of supplier homogeneity that creates tensions among alternative objectives within the cooperative. It can predicate an intergenerational conflict between old members, who have an incentive to convert the cooperative into a joint stock company, and young members, who benefit from the accumulated financial surpluses if the cooperative structure is maintained (Davis, 2001). The common 
property and horizon problems will be reduced when the value of processing facilities can be capitalized into upstream supplier asset prices (Porter and Scully, 1987, p. 49). We demonstrate how this proposition works and the particular circumstances under which it completely solves these problems.

Tying share ownership to input supplied, termed the nontransferability problem, has the effect of limiting the diversity of suppliers' investment portfolios and providing dispersed ownership shares. Limiting the diversity of portfolios will inhibit investment in the overrepresented cooperative business, whereas the inability to have shareholders with concentrated interests limits the effectiveness of management monitoring. ${ }^{4}$ It may also limit suppliers' willingness to invest retained earnings insofar as higher dividends constrain management where there is a weak link between ownership and control. ${ }^{5}$ Our intertemporal model illustrates that the payout mechamism to suppliers is a source of over-investment that may offset these effects.

Recent papers examining the efficiency of the cooperative structure include Hart and Moore (1998), who model the investment behavior of a nonprofit consumer cooperative in a static setting. Banerjee, et al. (2001) examine the effects on overall efficiency of rent-seeking behavior by heterogenous cooperative members. Cook and Iliopoulos (2000) discuss various ways in which tied-equity and intergenerational conflict between old and new members might be lessened. Some possible remedies include closed membership, equity redemption plans, and different classes of shares with different transferability properties. Harris, et al. (1996) and Cook and Iliopoulos (1999) describe a new form of cooperative in which membership is closed, new members are forced to purchase exiting members' stock, and delivery rights are proportional to members' equity stake. These models are fundamentally hybrids of cooperative and investor-owned firm governance structures. As such, their economic efficiency will depend upon the balance of contracting problems the cooperative may solve and the governance problems that it poses. Our approach admits these alternatives but solves the payout-induced inefficiency without a hybrid structure.

Section 2 introduces the basic components of our model and derives the level of production which maximizes industry profits. The next section presents a general model of a cooperative, identifies the equilibrium level of raw material production, and identifies the causes of under- and over-production. Three different cooperative structures are analyzed in Section 4 including one which leads to efficient production decisions by suppliers. One particular implementation of this cooperative structure is described in Section 5. We offer some concluding remarks in Section 6 .

\footnotetext{
${ }^{4}$ These factors together with the common property and horizon problems also impinge on the cooperative's ability to raise debt.

${ }^{5}$ See La Porta, Lopez-de-Silanes, Shleifer and Vishney (2000) for investor-owned firms' responses to wider gaps between ownership and control, and Faccio, Lang and Young (1999) for empirical evidence.
} 


\section{Model Set-up}

A total of $I$ suppliers produce a product which must be processed and marketed before it can be sold to consumers. Let $c_{i}^{f}(x, t)$ denote supplier $i$ 's cost of producing $x$ units of raw material in period $t$; let $C^{c}(Q, X, K, t)$ denote the cost in period $t$ of producing $Q$ units of finished product from $X$ units of raw material using $K$ units of capital; and let $R(Q, t)$ denote the revenue from selling $Q$ units of finished product in period $t .{ }^{6}$ We suppose that capital depreciates at rate $\delta$ and that all future cashflows are discounted at rate $r$.

When assessing the performance of the cooperative structure we use as a benchmark a verticallyintegrated firm comprising the suppliers of raw material and the producers of the final product. The present value of this firm's profits, denoted $W$, satisfies the Bellman equation

$$
\begin{array}{r}
W\left(K_{t-1}, t\right)=\sup _{K_{t}, Q_{t}, x_{i t}}\left\{R\left(Q_{t}, t\right)-C^{c}\left(Q_{t}, \sum_{i=1}^{I} x_{i t}, K_{t}, t\right)-\sum_{i=1}^{I} c_{i}^{f}\left(x_{i t}, t\right)\right. \\
\left.-\left(K_{t}-(1-\delta) K_{t-1}\right)+\frac{1}{1+r} W\left(K_{t}, t+1\right)\right\},
\end{array}
$$

where $x_{i t}$ is the level of production of supplier $i$ in period $t$. The first order conditions for this problem reduce to

$$
\begin{aligned}
0 & =-C_{K}^{c}\left(Q_{t}, X_{t}, K_{t}, t\right)-\frac{r+\delta}{1+r} \\
0 & =R_{Q}\left(Q_{t}, t\right)-C_{Q}^{c}\left(Q_{t}, X_{t}, K_{t}, t\right), \\
0 & =C_{X}^{c}\left(Q_{t}, X_{t}, K_{t}, t\right)+c_{i, x}^{f}\left(x_{i t}, t\right), \quad i=1, \ldots, I
\end{aligned}
$$

where

$$
X_{t}=\sum_{i=1}^{I} x_{i t}
$$

is the aggregate supply of the raw material in period $t$. These equations can be solved simultaneously each period to obtain the efficient levels of raw material $x_{i t}$ for each supplier, capital stock $K_{t}$, and final product $Q_{t}$.

Notice that the first two equations above are the first order conditions which result from the following maximization problem:

$$
G\left(X_{t}, t\right)=\sup _{K, Q}\left\{R(Q, t)-C^{c}\left(Q, X_{t}, K, t\right)-\frac{(r+\delta) K}{1+r}\right\}
$$

This function will prove very useful when we analyze the cooperative structure. It gives the net revenue from processing and marketing $X_{t}$ units of raw material, assuming that profit-maximizing processing decisions are made. If industry profits are to be maximized, supplier $i$ should produce $x_{i t}$ units of the raw material, where $x_{i t}$ satisfies

$$
c_{i, x}^{f}\left(x_{i t}, t\right)=G_{X}\left(X_{t}, t\right)
$$

\footnotetext{
${ }^{6}$ Wherever possible we use upper case letters to represent aggregate quantities and lower case letters to represent quantities related to individual suppliers. We use lower case letters for prices.
} 
That is, the marginal cost of producing raw material must equal the marginal net revenue from processing and marketing this raw material. It is convenient to introduce the inverse aggregate supply function for the raw material in period $t$. Denoted $m(X, t)$, it has the property that, for every $X$, the production levels $x_{i}$ defined by $m(X, t)=c_{i, x}^{f}\left(x_{i}, t\right)$ satisfy $\sum_{i=1}^{I} x_{i}=X$. That is, if suppliers sold their output of raw material for a price $m(X, t)$, they would supply $X$ units in total. Using the inverse aggregate supply function allows us to rewrite the efficiency condition as

$$
m\left(X_{t}^{e}, t\right)=G_{X}\left(X_{t}^{e}, t\right)
$$

It is straightforward to demonstrate that a social planner that sought to maximise dynamic efficiency (the sum of producers' and consumers' surplus into the future) would have exactly the same first order conditions with the exception of the replacement of marginal revenue with price. Nothing hinges on this difference for our analysis of the economic efficiency of cooperatives. ${ }^{7}$ Where economies of scale are such that very many competing cooperatives can exist in this market the (perfect competition) equilibrium conditions will obtain and marginal revenue will in fact equal price. Whether there are one or many cooperatives does not alter the source of, or solution we provide to, the resource misallocation of cooperatives.

\section{The Cooperative Equilibrium}

In this section we suppose that raw material is processed and marketed by a cooperative. Suppliers are able to supply any quantity of raw material to the cooperative, which distributes all profits to suppliers in proportion to the amount of raw material they supply. The cooperative makes processing decisions with the objective of maximizing profit subject to this payout mechanism, and in consequence maximises the payout. Suppliers must own one share in the cooperative for each unit of raw material supplied. We let $s_{t}$ denote the price of one share in the cooperative in period $t$, and let $w_{t}$ denote that period's payout per unit of raw material.

\subsection{The Suppliers' Problem}

A typical supplier takes the raw material payout as given and chooses the level of production which maximizes the value of their business. Let $f_{i}\left(w_{t}, s_{t}, t\right)$ denote the value of supplier $i$ 's business at the start of period $t$. If the supplier produces $x_{i t}$ units of raw material, at a cost of $c_{i}^{f}\left(x_{i t}\right)$, it must buy cooperative shares costing $x_{i t} s_{t}$. This earns the supplier a total payout of $w_{t} x_{i t}$. The cashflow in period $t$ therefore equals

$$
w_{t} x_{i t}-c_{i}^{f}\left(x_{i t}, t\right)-x_{i t} s_{t} .
$$

\footnotetext{
${ }^{7}$ If the cooperative is exporting output the profit-maximising marginal revenue condition will also be the condition for economic efficiency for the country of origin.
} 
At the start of the next period, the business will be worth $f_{i}\left(w_{t+1}, s_{t+1}, t+1\right)$ and the cooperative shares will be worth $s_{t+1} x_{i t}$. Therefore

$$
f_{i}\left(w_{t}, s_{t}, t\right)=\sup _{x_{i t}}\left\{w_{t} x_{i t}-c_{i}^{f}\left(x_{i t}, t\right)-s_{t} x_{i t}+\frac{1}{1+r}\left(f_{i}\left(w_{t+1}, s_{t+1}, t+1\right)+s_{t+1} x_{i t}\right)\right\} .
$$

The first order condition is

$$
c_{i, x}^{f}\left(x_{i t}, t\right)+\frac{r s_{t}}{1+r}=w_{t}+\frac{s_{t+1}-s_{t}}{1+r} .
$$

That is, the supplier should increase production until the marginal cost of producing the raw material plus the opportunity cost of holding cooperative shares equals the sum of the raw material payout and the capital gain expected from holding cooperative shares.

Solving the supplier's first order condition for $c_{i, x}^{f}\left(x_{i t}, t\right)$ and using the inverse aggregate supply function shows that the aggregate supply of raw material in period $t$, denoted $X_{t}$, satisfies

$$
m\left(X_{t}, t\right)=w_{t}-s_{t}+\frac{s_{t+1}}{1+r},
$$

where $m\left(X_{t}, t\right)$ is the supply price of $X_{t}$.

\subsection{The Cooperative's Problem}

The cooperative takes the quantity of raw material supplied as given, and processes this raw material in order to maximize the present value of the payout. Suppose that the cooperative ends period $t-1$ with $X_{t-1}$ shares on issue, $K_{t-1}$ units of capital, and debt of $D_{t-1}$. Suppliers provide $X_{t}$ units of raw material during period $t$, the cooperative pays $K_{t}-(1-\delta) K_{t-1}$ in order to increase its capital stock, and borrowing increases by $D_{t}-(1+r) D_{t-1}$. The cooperative receives an equity injection of $\left(X_{t}-X_{t-1}\right) s_{t}$ from new and existing members. Thus, the total raw material payout in period $t$ is 8

$$
\begin{aligned}
w_{t} X_{t}= & R\left(Q_{t}, t\right)-C^{c}\left(Q_{t}, X_{t}, K_{t}, t\right) \\
& -\left(K_{t}-(1-\delta) K_{t-1}\right)+\left(D_{t}-(1+r) D_{t-1}\right)+s_{t}\left(X_{t}-X_{t-1}\right) .
\end{aligned}
$$

Rewriting this equation in the form

$$
K_{t}-(1-\delta) K_{t-1}=\underbrace{R\left(Q_{t}, t\right)-C^{c}\left(Q_{t}, X_{t}, K_{t}, t\right)-w_{t} X_{t}}_{\text {retained earnings }}+\underbrace{D_{t}-(1+r) D_{t-1}}_{\text {borrowing }}+\underbrace{s_{t}\left(X_{t}-X_{t-1}\right)}_{\text {new equity }}
$$

makes it clear that the cooperative funds its investment through a mixture of retained earnings, borrowing, and equity injections.

\footnotetext{
${ }^{8}$ Banerjee, et al. (2001) allow the cooperative to depress prices and divert some of the resulting retained earnings to benefit particular suppliers. In common with a key characteristic of cooperatives, all suppliers are treated equally in our model. In particular, all receive the same payment per unit of raw material supplied.
} 
Let $V\left(K_{t-1}, D_{t-1}, X_{t-1}, t\right)$ denote the present value of all future raw material payouts measured as at period $t$. Assuming the cooperative's aim is to maximize the present value of the raw material payout, $V$ must satisfy

$$
\begin{aligned}
& V\left(K_{t-1}, D_{t-1}, X_{t-1}, t\right)=\sup _{K_{t}, Q_{t}, D_{t}}\left\{w_{t} X_{t}+\frac{1}{1+r} V\left(K_{t}, D_{t}, X_{t}, t+1\right)\right\} \\
&=\sup _{K_{t}, Q_{t}, D_{t}}\{ R\left(Q_{t}, t\right)-C^{c}\left(Q_{t}, X_{t}, K_{t}, t\right) \\
&-K_{t}+(1-\delta) K_{t-1}+D_{t}-(1+r) D_{t-1} \\
&\left.+s_{t}\left(X_{t}-X_{t-1}\right)+\frac{1}{1+r} V\left(K_{t}, D_{t}, X_{t}, t+1\right)\right\} .
\end{aligned}
$$

First order conditions are ${ }^{9}$

$$
\begin{aligned}
& 0=-C_{K}^{c}\left(Q_{t}, X_{t}, K_{t}, t\right)-\frac{r+\delta}{1+r}, \\
& 0=R_{Q}\left(Q_{t}, t\right)-C_{Q}^{c}\left(Q_{t}, X_{t}, K_{t}, t\right) .
\end{aligned}
$$

Notice that the first order conditions (8) and (9) are identical to the corresponding conditions for the vertically-integrated firm, equations (1) and (2) respectively. ${ }^{10}$ Thus, the cooperative makes the same processing and capital decisions as the vertically-integrated firm would make if the firm received the same amount of raw material from its suppliers. However, as we will now show, the cooperative structure generally gives its members an incentive to supply an inefficient amount of raw material. Inefficiency comes from suppliers' production decisions, rather than the cooperative's processing decisions.

\subsection{Equilibrium}

The equilibrium values of $\left(K_{t}, Q_{t}, w_{t}, X_{t}\right)$ are defined by equations (6)-(9). Equations (8) and (9) imply that $K_{t}=K^{*}\left(X_{t}, t\right)$ and $Q_{t}=Q^{*}\left(X_{t}, t\right)$ are identical to the policies followed by a verticallyintegrated firm. Therefore equation (7) can be written as

$$
w_{t} X_{t}=G\left(X_{t}, t\right)-\frac{1-\delta}{1+r}\left(K_{t}-(1+r) K_{t-1}\right)+\left(D_{t}-(1+r) D_{t-1}\right)+s_{t}\left(X_{t}-X_{t-1}\right) .
$$

Eliminating $w_{t}$ between this and equation (6) gives a single condition for the equilibrium level of raw material production: ${ }^{11}$

$$
m\left(X_{t}, t\right)+\frac{1}{X_{t}} \cdot \frac{U_{t+1}-U_{t}}{1+r}=\frac{G\left(X_{t}, t\right)}{X_{t}}+\frac{1}{X_{t}} \cdot \frac{r U_{t}}{1+r}
$$

where

$$
U_{t}=(1-\delta) K_{t-1}-(1+r) D_{t-1}-s_{t} X_{t-1}
$$

\footnotetext{
${ }^{9}$ The first order condition for $D_{t}$ is an identity, so that the level of debt has no effect on the present value of the raw material payout.

${ }^{10}$ In particular, the optimal level of capital stock depends on the quantity of raw material supplied, but not on the cooperative's share price. Processing decisions do not depend directly on the cooperative's capital structure.

${ }^{11}$ In the static model of Helmberger and Hoos (1962), the equilibrium condition is essentially $m(X)=G(X) / X$.
} 
In order to better understand the meaning of this variable, consider the situation at the start of period $t$. The cooperative has capital of $(1-\delta) K_{t-1}$, but owes bondholders $(1+r) D_{t-1}$. The nominal value of suppliers' shares in the cooperative equals $s_{t} X_{t-1}$. Therefore $U_{t}$ equals the amount of shareholders' funds that is held by the cooperative at the start of period $t$ but for which no shareholder has title. We term $U_{t}$ unowned capital.

Comparing equations (3) and (10) highlights the three sources of inefficiency in the cooperative structure.

Cross subsidies. Efficiency requires that the marginal cost of producing raw material equals marginal revenue. However, because all suppliers are treated equally, they supply raw material until the marginal cost equals average revenue. Thus, profits from the cooperative's other activities are used to subsidize losses from over-production. ${ }^{12}$

The other two sources of inefficiency derive from the cooperative's unowned capital stock. This capital stock is financed using retained earnings (that is, a lower raw material payout). The cost is therefore shared according to the amount of raw material supplied at the time the investment is made. In contrast, the returns generated by unowned capital are allocated according to the amount of raw material supplied at the time the returns are distributed. These two factors distort raw material production in different ways.

Sharing the cost of unowned capital. If a member temporarily reduces her supply of raw material, she reduces her contribution to the cooperative's investment in processing assets, without reducing her entitlement to the future returns generated by these assets. This encourages under-production.

Sharing the return on unowned capital. Recall that $G\left(X_{t}, t\right)$ is the net revenue from processing and marketing raw material, assuming that the cooperative must rent its entire capital stock. However, if capital worth $U_{t}$ is unowned, the cooperative saves $r U_{t}$. This saving is passed onto suppliers in the form of a higher payout for raw material. Because this 'dividend' is distributed according to the amount of raw material currently supplied, and not according to the amount of capital originally contributed, farmers have an incentive to over-produce.

The situation is shown in Figure 1, where $X^{e}$ is the amount of raw material production which maximizes the profit of the vertically-integrated firm and $X^{c}$ is the level of production in the cooperative equilibrium. If the stock of unowned assets is growing (in present value terms), the distortions due to unowned capital offset the effect of cross subsidies.

\footnotetext{
${ }^{12}$ If net revenue is a concave function of the quantity of raw material, $G\left(X_{t}, t\right) / X_{t}>G_{X}\left(X_{t}, t\right)$, and the cooperative equilibrium results in over-production.
} 
Figure 1: Efficiency of the cooperative

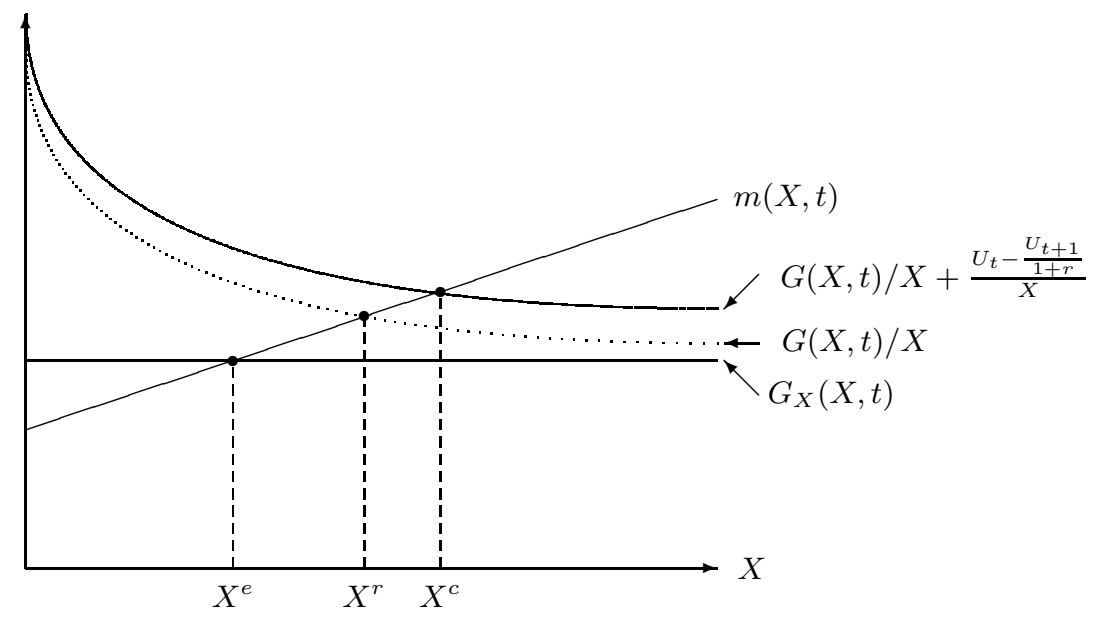

\subsection{The Horizon Problem}

We conclude Section 3 by calculating the value of each supplier's business, and using this value to discuss the horizon problem.

The value of supplier $i$ 's business can be found by substituting the equilibrium value of $w_{t}$ into (4):

$$
f_{i}\left(w_{t}, s_{t}, t\right)=\frac{x_{i t}}{X_{t}}\left(G\left(X_{t}, t\right)+U_{t}-\frac{U_{t+1}}{1+r}\right)-c_{i}^{f}\left(x_{i t}, t\right)+\frac{f_{i}\left(w_{t+1}, s_{t+1}, t+1\right)}{1+r} .
$$

Recursive substitution shows that at time $t$ the business is worth

$$
\begin{aligned}
f_{i}\left(w_{t}, s_{t}, t\right)= & \sum_{j=0}^{\infty} \frac{1}{(1+r)^{j}}\left(\left(\frac{x_{i, t+j}}{X_{t+j}}\right) G\left(X_{t+j}, t+j\right)-c_{i}^{f}\left(x_{i, t+j}, t+j\right)\right) \\
& +\left(\frac{x_{i t}}{X_{t}}\right) U_{t}-\sum_{j=1}^{\infty} \frac{1}{(1+r)^{j}}\left(\frac{x_{i, t+j-1}}{X_{t+j-1}}-\frac{x_{i, t+j}}{X_{t+j}}\right) U_{t+j} .
\end{aligned}
$$

The value of each supplier's business is made up of three terms. The first is the value of producing and processing raw material; the second is a fraction of the shareholders' funds currently held by the cooperative but for which no shareholder has title, where the fraction is the proportion of shares held by the supplier; the third component is an adjustment reflecting future capital contributions which will be lost on exiting the cooperative. The value of unowned capital is thus, to some extent, capitalized into the value of suppliers' businesses.

Consider the special case where the proportion of raw material produced by supplier $i$ is constant over time, so that $x_{i t}=\lambda_{i} X_{t}$ for some constant $\lambda_{i}$. Then the value of supplier $i$ 's business is

$$
f_{i}\left(w_{t}, s_{t}, t\right)=\sum_{j=0}^{\infty} \frac{1}{(1+r)^{j}}\left(\lambda_{i} G\left(X_{t+j}, t+j\right)-c_{i}^{f}\left(x_{i, t+j}, t+j\right)\right)+\lambda_{i} U_{t}
$$


and the value of this supplier's unowned capital is capitalized into the value of her business. This eliminates the horizon problem. It disappears because the value of the cooperative's unowned assets is capitalized into the value of suppliers' businesses. ${ }^{13}$ Thus, although the sale of shares does not compensate an exiting supplier for her loss of returns to the cooperative's unowned capital, the sale of her business does provide compensation.

In general, however, the proportion of raw material supplied by an individual member can fluctuate over time. ${ }^{14}$ Equation (11) shows the effect on the value of suppliers' businesses. For example, if a member will provide a decreasing proportion of the total supply of raw material in the future (that is, $x_{i, t+j-1} / X_{t+j-1}>x_{i, t+j} / X_{t+j}$ ), then the value of the business must be adjusted downwards. This reflects the fact that the supplier is currently providing a relatively large proportion of the cooperative's capital (via retained earnings), but will get a relatively small proportion of the benefit (via a higher raw material payout) in the future. Conversely, the value of growing businesses will include more than their fair share of unowned capital.

However, the two effects cancel when summed over all members of the cooperative. In fact, summing equation (11) over $i$ and letting $F=\sum_{i=1}^{I} f_{i}$ denote the aggregate value of suppliers' businesses shows that

$$
F\left(w_{t}, s_{t}, t\right)=\sum_{j=0}^{\infty} \frac{1}{(1+r)^{j}}\left(G\left(X_{t+j}, t+j\right)-\sum_{i=1}^{I} c_{i}^{f}\left(x_{i, t+j}, t+j\right)\right)+U_{t} .
$$

This confirms that unowned capital is capitalized into the value of suppliers' businesses in aggregate.

\section{Different Share Pricing Regimes}

The precise cooperative equilibrium depends on the path of the value of unowned capital, and hence on both the cooperative's share price and its level of debt. ${ }^{15}$ We consider three possible share-price setting mechanisms in this section, and describe the level of production and the impact on the value of inputs in each case.

\footnotetext{
${ }^{13}$ This point has been proposed by Vitaliano (1983).

${ }^{14}$ Suppliers' shares of aggregate input supply will only fluctuate over time, given the first order conditions, if the cost functions vary across suppliers. Some variation is implied by the existence of an increasing supply price for the input, but they may vary in other respects as well. For example, in some circumstances they may vary with the age and ability of the management of the supplier's business and this could generate variations in output across suppliers. In this event, the market value of a supplier business will depend upon the characteristics of potential buyers, instead of the existing suppliers for whom valuations are depicted in (11).

${ }^{15}$ We found earlier that, for a given amount of raw material supplied, the cooperative's debt level has no effect on its processing decisions. However, in equilibrium the level of debt does matter. Changing debt levels change the amount of unowned capital and therefore change members' supply decisions.
} 


\subsection{Nominal Share Values}

Traditionally, membership of a cooperative is free. (That is, $s_{t}=0$ for all $t$.) Unless extremely high debt levels are adopted, over time the amount of shareholders' funds for which no ownership rights exist will become considerable. The result is likely to be an inefficient level of raw material production. The cost of the assets used to process their raw material, as well as the value added by the cooperative, is reflected in the value of suppliers' businesses.

\subsection{Valuing Capital at Replacement Cost}

An alternative is to set the share price in such a way that all capital, when valued at replacement cost, is accounted for. The cooperative's processing assets are valued at replacement cost, and the value of suppliers' equity is set equal to the difference between this replacement cost and outstanding debt. That is, the share price is set equal to

$$
s_{t}=\frac{(1-\delta) K_{t-1}-(1+r) D_{t-1}}{X_{t-1}}
$$

at the start of period $t$, ensuring that $U_{t}=0$. While this policy eliminates the investment-based sources of inefficiency, the effect of cross subsidies remains. Suppliers now (over-) produce raw material to the point where

$$
m\left(X_{t}, t\right)=\frac{G\left(X_{t}, t\right)}{X_{t}} .
$$

In Figure 1, this corresponds to $X^{r}$ units of raw material.

When they buy shares in a cooperative, members pay for the assets used to process their raw material. The value added by the cooperative when processing this raw material is reflected in the value of suppliers' businesses.

\subsection{Fair Value Share Pricing}

The previous two schemes propose share prices that have an artificial basis. Neither reflect the success or failure of the cooperative business except insofar as the business is financially viable. Fair value share pricing seeks to mimic the price that would obtain if the shares were freely traded. The form of cooperative, described here, retains the feature that share ownership is tied to raw material supplied but it has two key innovations.

Unbundling. The cooperative pays suppliers the wholesale price of raw material $m_{t}^{*}$ for each unit they supply, and pays shareholders a dividend of $v_{t}$ dollars per share.

Fair share values. A third party values the shares at the present value of all future dividend payments. This implies that

$$
s_{t}=v_{t}+\frac{1}{1+r} s_{t+1} .
$$


Consider how this alters the problem faced by a typical supplier. The analysis leading up to equation (5) still applies, provided we replace the raw material payout $w_{t}$ with $m_{t}^{*}+v_{t}$ everywhere. The supplier's first order condition becomes

$$
m_{t}^{*}+v_{t}+\frac{s_{t+1}-s_{t}}{1+r}=c_{x}^{f}\left(x_{t}, t\right)+\frac{r s_{t}}{1+r}
$$

Now, however, the opportunity cost of holding cooperative shares exactly matches the benefit from holding shares. Therefore,

$$
c_{x}^{f}\left(x_{t}, t\right)=m_{t}^{*}
$$

as can be seen by substituting (12) into the supplier's first order condition. The aggregate supply of raw material satisfies $m\left(X_{t}, t\right)=m_{t}^{*}$. In particular, the aggregate supply of raw material is independent of the cooperative structure, depending only on the wholesale price of the raw material and suppliers' cost functions.

As before, the cooperative takes suppliers' production decisions as given. The total payout to shareholders in period $t$ is

$$
\begin{aligned}
v_{t} X_{t}= & R\left(Q_{t}, t\right)-m_{t}^{*} X_{t}-C^{c}\left(Q_{t}, X_{t}, K_{t}, t\right) \\
& -\left(K_{t}-(1-\delta) K_{t-1}\right)+\left(D_{t}-(1+r) D_{t-1}\right)+s_{t}\left(X_{t}-X_{t-1}\right) .
\end{aligned}
$$

Solving this equation for $X_{t-1} s_{t}$, and using (12) to eliminate $v_{t}$, shows that the value of shareholders' equity at the start of period $t$ is

$$
\begin{aligned}
X_{t-1} s_{t}= & R\left(Q_{t}, t\right)-m_{t}^{*} X_{t}-C^{c}\left(Q_{t}, X_{t}, K_{t}, t\right) \\
& -\left(K_{t}-(1-\delta) K_{t-1}\right)+\left(D_{t}-(1+r) D_{t-1}\right)+\frac{X_{t} s_{t+1}}{1+r} .
\end{aligned}
$$

The cooperative makes its processing decisions in order to maximize the value of shareholders' stake in the cooperative. That is, it solves

$$
\begin{aligned}
& Z\left(K_{t-1}, D_{t-1}, X_{t}, t\right)=\sup _{D_{t}, K_{t}, Q_{t}}\left\{R\left(Q_{t}, t\right)-C^{c}\left(Q_{t}, X_{t}, K_{t}, t\right)-m_{t}^{*} X_{t}\right. \\
& -\left(K_{t}-(1-\delta) K_{t-1}\right)+\left(D_{t}-(1+r) D_{t-1}\right) \\
& \left.+\frac{1}{1+r} Z\left(K_{t}, D_{t}, X_{t+1}, t+1\right)\right\}
\end{aligned}
$$

where $Z\left(K_{t-1}, D_{t-1}, t\right)$ is the value of shareholders' stake in the cooperative at the start of period $t$. First order conditions for the maximization problem are the same as for the vertically-integrated firm, (1) and (2). Since $m_{t}^{*}$ equals the wholesale price of the raw material, equation (3) is satisfied and industry profits are maximized.

The inefficiency has disappeared because the opportunity to capture another supplier's returns by supplying more raw material to the cooperative has been eliminated. The cooperative's share price now reflects the value of all of its assets, so that new members pay for the future flow of 
returns when they buy shares in the cooperative. In period $t$ the share price is

$$
s_{t}=\frac{(1-\delta) K_{t-1}-(1+r) D_{t-1}}{X_{t-1}}+\sum_{j=0}^{\infty} \frac{1}{(1+r)^{j}}\left(\frac{G\left(X_{t+j}, t+j\right)-m_{t+j}^{*} X_{t+j}}{X_{t-1}}\right) .
$$

Thus the current members of the cooperative own the capital stock (less outstanding debt) and the rights to all future profits. When new members buy shares in the cooperative, they pay a fair price for the assets used to process the raw material and the value added by the cooperative when processing this raw material. The values of suppliers' businesses reflect the profitability of producing raw material only. In fact, at the start of period $t$ supplier $i$ 's business has value

$$
f_{i}\left(m_{t}, t\right)=\sum_{j=0}^{\infty} \frac{1}{(1+r)^{j}}\left(m_{t+j}^{*} x_{i, t+j}-c_{i}^{f}\left(x_{i, t+i}, t+j\right)\right) .
$$

\section{$5 \quad$ Pricing Practice}

We have shown that if (i) the raw material is priced at its market value, and (ii) shares are priced at the present value of prospective downstream earnings, then the cooperative's payment of returns per unit of this input will not distort resource allocation. In certain circumstances this will yield an allocatively efficient industry, even though shares are tied to the amount of input supplied. This will not be achieved by pricing shares at some nominal value. Bonin et al. (1993) report that the Mondragon group of cooperatives in Spain, and plywood cooperatives in the U.S. Pacific North West implement "market-like" share transactions. However, the Mondragon group share prices are such that there is excess demand for entry and prospective entrants are screened by existing members. Thus they do not fit the fair value scheme we describe.

A member leaving a plywood cooperative consults with other members and a bank that determines the expected flow of income that is then discounted to obtain the value of shares. Craig and Pencavel (1992) argue that the share prices are substantially discounted from market prices in this calculation, and that the inability of members to pay high share prices is a rationale for the conversion of producer-cooperative mills into conventional structures (Bonin et al. 1993, p. 1295).

In 2001 a very large dairy cooperative was formed in New Zealand by the merger of two large dairy cooperatives and the entity that had held the sole statutorial right to export and control all exports of dairy products. The resulting vertically-integrated company, Fonterra Co-operative Group, processes $95 \%$ of New Zealand's raw milk and exports almost all of its product. The merger posed competition law issues which were ameliorated by a concomitant regulatory change removing all statutory impediments to exporting. In addition, regulations prohibit Fonterra from closing entry and exit options to potential and actual suppliers so long as its market share remains above $85 \% .{ }^{16}$ The company has a shareholders' council of approximately 40 elected suppliers responsible

\footnotetext{
${ }^{16}$ Open entry of suppliers means that any potential supplier can enter the cooperative providing its milk meets well-defined quality levels and it lies within the existing catchment of suppliers. Open exit means that suppliers can leave and be paid their share capital within a very short time of resigning.
} 
for monitoring the Board and appointing both a complaints management agent and an agent to set the milk and share price.

The formation of Fonterra was the culmination of eighty years during which the 500 dairy cooperatives of 1920 collapsed to one cooperative and several much smaller milk processing entities. The practices of nominal share pricing and of tying share ownership to milk supplied had been common. Tying is retained in Fonterra. However, under its constitution Fonterra is required to distinguish the payment for milk from the earnings of investment in processing, marketing and distribution, and to value the shares based upon these earnings and a payment for milk that is the wholesale price.

As with any market dominated by vertical integration, the New Zealand wholesale milk market is quite undeveloped and does not provide useful price signals. Fonterra's solution is to delegate the right to set the milk price and value shares to a valuer appointed by the shareholders' council. ${ }^{17}$ The valuer can choose its estimation procedure, but it is clear from Fonterra's constitution that it should produce an estimate of the wholesale price of raw milk. In the absence of a wholesale market, and the preponderance of export transactions, the valuer has chosen to take a portfolio of commodity dairy products, price them in international markets that are open to competition, convert these prices to New Zealand dollars at contemporary exchange rates, subtract the estimated least-cost processing cost, and call the resultant price the commodity milk price. ${ }^{18}$ The valuer then projects Fonterra's sustainable earnings into the future, based on a cost for milk supplied to the company by shareholders equal to the commodity milk price. The present value of this stream is the share valuation of the company. The actual milk payout to farmers may differ in explainable ways from the valuer's commodity milk price (for example, if the product mix or cost-efficiency of Fonterra differs from those of the valuer) and the actual dividend paid will differ from the valuer's earnings by retained earnings and other factors such as Fonterra's cost efficiency. The actions of Fonterra affect its share valuation by the earnings generated by investments. The effect of Fonterra's strategic decisions, and efficiency of production marketing and distribution, is captured in the amount of capital retained earnings represents and in the concomitant earnings stream.

The independent valuation process creates exactly equation (12) and eliminates the source of nominal share value inefficiency. The result is that entering suppliers buy shares for a price reflecting the expected stream of earnings from processing, marketing and distribution. These earnings will reflect temporary profits and losses as the company's fortunes fluctuate and any persistent profits that result from patents and market impediments to entry. A supplier that leaves the company receives payment for the shares that they surrender. Entry and exit is then determined by suppliers comparing the cost of entry to the estimate of the wholesale milk price,

\footnotetext{
${ }^{17}$ Currently the valuer is Standard and Poors.

${ }^{18}$ As a wholesale market evolves it may well be that the valuer will use a market-determined wholesale milk price in the future.
} 
despite the fact that their shares are tied to the amount of milk they supply.

Commodity milk prices fluctuate significantly and are quite uncertain. Entry and exit decisions will be based on expectations of company earnings as well as of the milk price and the prices of alternative products suppliers are able to produce. The valuer reports a range of commodity milk prices and concomitant valuations. The company is expected to choose a scenario in the range, and to justify any choice that is not the midpoint reported by the valuer. If ever the market expectation of future prospects differ significantly from that reflected in the share valuations, entry and exit decisions may be based on factors other than the reported wholesale price of milk and supplier marginal cost. While such a circumstance is unlikely to persist, it could be important over short periods. Because any supplier can enter (leave) Fonterra and buy (sell) shares at the fair value price, Fonterra has every incentive to ensure that the price of milk is in fact an estimate of the wholesale price: the share value follows from this. The company does not want to induce non-profit-enhancing entry or exit of raw material supply.

\section{Concluding Remarks}

Our analysis has been based upon unrestricted entry and exit from the cooperative. The allocative inefficiency of cooperative supplier payment schedules may not arise under restricted entry. However, providing processing distribution and marketing scale economies are small relative to the market, competition among cooperatives will result in a situation that is equivalent to open entry and exit of suppliers, including retention of the allocative inefficiency that we have described. Cooperative-specific profit-preserving entry restrictions will engender cooperative entry and not enable excess profitability to be maintained by any individual cooperative. In this circumstance, each co-operative's marginal revenue will in fact be price, but the distortions engendered by the tying of payout and shares to input supply will remain unless shares are priced at their "fair value". There will be an incentive to adopt fair value pricing in that it produces higher profits, but cooperative structures are adopted for reasons that include the solution to contracting problems between suppliers and processors. The possibility of adopting fair value share pricing means that there is potential for the cooperative solution to entail no allocative inefficiency, although there are likely to be residual inefficiencies flowing from share ownership and the governance structure that will have to be balanced against any contracting problems solved.

We have shown that it is sufficient for efficient input processing by a cooperative, where its share ownership is tied to input supply, that its share price is the present value of its expected earnings and suppliers decide whether to enter or leave solely on the basis of the profitability of cooperative membership. The aggregate level of supplier input processed by such a cooperative will commonly be less than if shares are not fully priced (for example, if they are priced at capital replacement) and less than if they possess unowned capital (where unowned capital must exist in 
aggregate under nominal share pricing). It is these effects on input provided by suppliers that is the origin of inefficiency, and not investment decision-making.

The value of the supplier business incorporates unowned capital, although in the presence of open entry the attachment of unowned capital to any particular input will depend upon that input's relative scarcity. When entry to the cooperative is free, new members pay for the assets used to process their milk, as well as the value added by the cooperative, when they buy their business; when cooperative shares reflect the past cost of building up the cooperative's processing assets, the value added by the cooperative is capitalized into supplier business prices. However, under fair value share pricing, business values reflect the profitability of selling the input on the wholesale market, and new (exiting) members pay for (sell) the processing assets and the value added by these assets when they buy (sell) their shares in the cooperative.

Intergenerational conflict discussed by Cook and Iliopoulos (2000) and Davis (2001), for example, does not arise even under nominal share pricing where production is inefficient, since shareholders receive the value of unowned capital when selling their business. Indeed, converting the cooperative to a traditional corporate (de-mutualising) would not result in any windfall gains: all else constant, the apparent windfall gain to cooperative shareholders would be offset by the elimination of unowned capital and possibly a drop in the value of other inputs. Utilising the supplier value equations (4) or (11) it can be shown that an increase in the nominal share value reduces the value of the suppliers' unowned capital. Furthermore, this is offset by higher profits produced by the more efficient supply of raw material. Indeed, excepting the extremely unlikely event that under-production has been induced by rapid cooperative growth under nominal share pricing, the increase in the nominal price will increase the profitability of the vertically-integrated cooperative and thereby its valuation. In short, the method of payout, unless based upon fair value share pricing, will entail the application of any infra-marginal rents the co-operative earns to the input supplied and induce distortions in supply that reduce supplier production efficiency.

\section{References}

Andersen, Richard K., Philip K. Porter, and S. Charles Maurice, "The economics of consumer managed firms." Southern Economic Journal, 46(1), 1979, 119-130.

Banerjee, Abhijit V., Kaivan D. Munshi, Dilip Mookherjee, and Debraj Ray (2001). "Inequality, control rights, and rent seeking: Sugar cooperatives in Maharashtra." Journal of Political Economy 109(1), 138-190.

Bonin, John P., Derek C. Jones, and Louis Putterman (1993). "Theoretical and empirical studies of producer cooperatives: Will ever the twain meet?" Journal of Economic Literature 31, $1290-1320$ 
Cook, Michael L. and Constantine Iliopoulos (1999). "Beginning to inform the theory of the cooperative firm: Emergence of the new generation cooperative." Finnish Journal of Business Economics 4, 525-535.

Cook, Michael L. and Constantine Iliopoulos (2000). "Ill-defined property rights in collective action: the case of US agricultural cooperatives." In C. Ménard (ed.), Institutions, Contracts and Organizations: Perspectives from New Institutional Economics, Cheltenham: Edward Elgar.

Craig, Ben and John Pencavel (1992). "The behavior of worker cooperatives: The plywood companies of the Pacific Northwest." American Economic Review 82(5), 1083-1105.

Davis, Kevin (2001). "Credit union governance and survival of the cooperative form." Journal of Financial Services Research 19(2/3), 197-210.

Harris, Andrea, Brenda Stefanson, and Murray Fulton (1996). "New generation cooperatives and cooperative theory." Journal of Cooperatives 11, 15-29.

Hart, Oliver and John Moore (1996). "The governance of exchanges: Members' cooperatives versus outside ownership." Oxford Review of Economic Policy 12(4), 53-69.

Hart, Oliver and John Moore (1998). "Cooperatives vs. outside ownership." NBER Working Paper 6421.

Helmberger, Peter and Sidney Hoos (1962). "Cooperative enterprise and organization theory." Journal of Farm Economics 44(2), 275-290.

Jensen, Michael C. and William H. Meckling (1979). "Rights and production functions: An application to labor managed firms and codetermination." Journal of Business 52(4), 469506.

Porter, Philip K. and Gerald W. Scully (1987). "Economic efficiency in cooperatives." Journal of Law and Economics 30, 489-512.

Vitaliano, Peter (1983). "Cooperative enterprise: An alternative conceptual basis for analyzing a complex institution." American Journal of Agricultural Economics 65(5), 1078-1083.

Ward, B. (1958). "The firm in Ilyria: Market syndicalism." American Economic Review 48, $566-589$. 